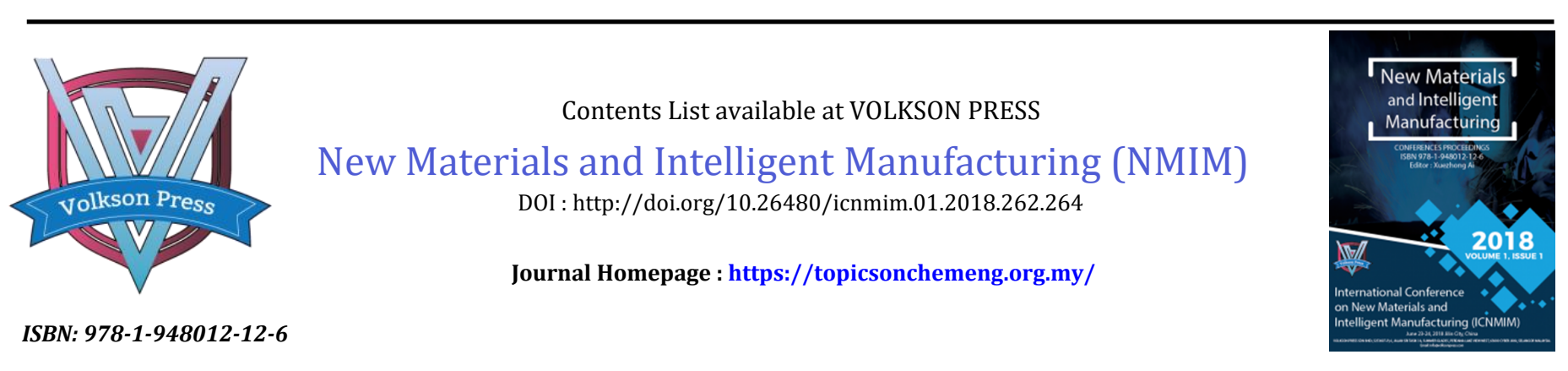

\title{
FRICTION WELDING OF HIGH-NB TIAL ALLOY AND 40CR STEEL RODS
}

\author{
Xin Wang, Minghao Liang, Dayong Lu* \\ Key Laboratory for Special Functional Materials in Jilin Provincial Universities, Jilin Institute of Chemical Technology Chengde Street 45, \\ Jilin 132022, China. \\ *Corresponding Author Email: dylu@jlict.edu.cn
}

This is an open access article distributed under the Creative Commons Attribution License, which permits unrestricted use, distribution, and reproduction in any medium, provided the original work is properly cited

\section{ARTICLE DETAILS}

\section{Article History:}

Received 26 June 2018

Accepted 2 july 2018

Available online 1 August 2018

\section{ABSTRACT}

High-Nb TiAl alloy and 40Cr steel rods were welded together using friction welding method. The microstructure and microhardness distribution of the interface of the welded joint were investigated. The tensile strengths of the welded joints in as-welded and in annealing state were determined. The results indicated that the friction welding is an effective method for achieving the solid joint between high- $\mathrm{Nb} \mathrm{TiAl}$ alloy and $40 \mathrm{Cr}$ steel. The tensile strength of as-welded joint reached about $150 \mathrm{MPa}$, and fracture occurred at the interface. However, after annealing at $500^{\circ} \mathrm{C}$ for $10 \mathrm{~h}$, the tensile strength of the joint reached about $400 \mathrm{MPa}$, and fracture occurred on the high- $\mathrm{Nb}$ TiAl alloy side. The microhardness at the welded interface was much higher than those of the $40 \mathrm{Cr}$ steel and high-Nb TiAl alloy in as-welded state.

\section{KEYWORDS}

High-Nb TiAl alloy, 40Cr steel, friction welding, microstructure, mechanical properties.

\section{INTRODUCTION}

TiAl alloys are regarded as potential candidates for replacing heavier high temperature materials in areospace engines due to their excellent properties, such as low density, high specific strength, good high temperature mechanical properties and oxidation resistance [1,2]. Recently, researchers found a new TiAl alloy with high $\mathrm{Nb}$ containing that have higher high temperature strength and oxidation resistence than conventional TiAl alloy [3,4]. High quality of joints between high-Nb TiAl alloy itself and other metal materials such as steels are particularly improtant to produce aerospace engine components. Welding and joining of high $\mathrm{Nb}$-TiAl alloy is still one of the keys to its for elevated-temperature aerospace and automotive applications. However few investigations on the dissimilar joining between high-Nb TiAl alloy and $40 \mathrm{Cr}$ steel are reproted.

Some welding methods have been reported for joining TiAl alloy to steel, such as diffusion bonding and brazing $[5,6]$. However, the quality of the joint between TiAl alloy and steels are usually poor when using fusion welding because of solidfication cracks and high internal stress. Solid state welding such as difusion bonding and brazing can avoid these problems and obtain good joint properties. Although difusion bonding and brazing are effective for welding TiAl and steels, these methods require vacuum equipment and inert atmosphere, which limits the application of these welding methods. Furthemore, the long welding time and high costs restrict its practical application. Friction welding is a solid state joining technique, which has many advantages such as less process time, energy and materials are wasted [7]. During friction welding, a great deal of heat is generated, the two contact rods are softened and joined together. However, the low ductility of high-Nb TiAl alloy would be a challenge to obtain satisfied joint. The present work is devoted to conducting friction welding of high-Nb TiAl alloy to $40 \mathrm{Cr}$ steel, and investigating the microstructure and mechanical properties of the welding joints.

\section{EXPERIMENTAL}

The nominal composition of the TiAl alloy and $40 \mathrm{Cr}$ steel, used in this experiment, were Ti-45Al-8.5Nb-0.2W-0.2B-0.02Y (atomic fraction, \%) and $\mathrm{Fe}-0.9 \mathrm{C}-0.6 \mathrm{Mn}-0.4 \mathrm{Cr}-0.3 \mathrm{Si}$ (mass fraction, \%). The length of rods were $125 \mathrm{~mm}$, and the diameter were $10 \mathrm{~mm}$. Before friction welding, the contact interfaces of the two rods were polished with SiC papers and the cleaned by ethanol. Friction was carried out using friction welder with a constant rotating speed $(1500 \mathrm{rev} / \mathrm{min})$. The friction parameters were friction pressure $(2.5 \mathrm{KN})$, friction time $(2 \mathrm{~s})$, upset pressure $(3.5 \mathrm{KN})$ and upset time $(5 \mathrm{~s})$. After welding part of the joints were heat treated at $500^{\circ} \mathrm{C}$ for $10 \mathrm{~h}$ with a heat rate of $10 \mathrm{~K} / \mathrm{min}$, and then cooled down to ambient temperature in furnace.

X-ray diffraction (XRD) measurements were performed using a Rint 2200 X-ray diffractometer (Rigaku). XRD data were collected between $20^{\circ} \leq 2 \theta$ $\leq 85^{\circ}$ in steps of $0.02^{\circ}$ at ambient temperature. Microstructure analyses of the friction interfaces were conducted by optical microscope (OM) and scanning electron microscope (SEM) employing the black scattered (BSE) imaging mode. Microhardness distribution around the weld interfaces were detected by Vickers hardness testing machine. Samples for microscopic examination were prepared by standard metallographic polishing procedures. Tensile test was performed on the universal tensile machine. Microanalysis was detected by electron probe X-ray microanalyser (EPMA).

\section{RESULTS AND DISCUSSION}

Figure 1 shows the welded joint between high-Nb TiAl alloy and $40 \mathrm{Cr}$ steel rods. The flash was symmetrically formed by the deformed and forged of hot metal under forged pressure around the interface.

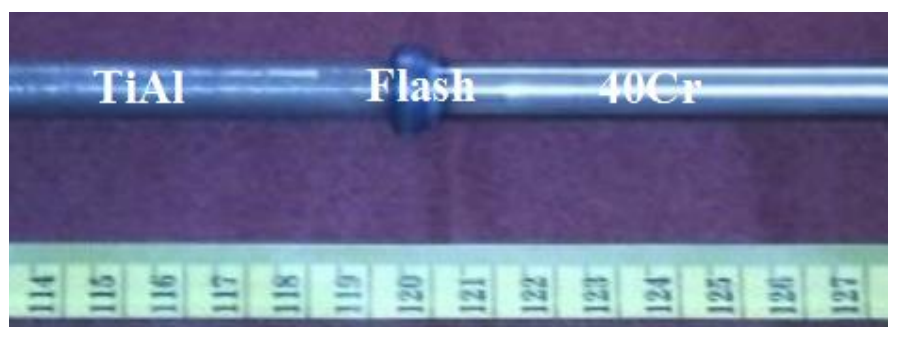

Figure 1: Welded joint between high-Nb TiAl alloy and 40Cr steel rods. 


\subsection{Mechanical Properties}

Figure 2 shows the failure joints after tensile test. The tensile strength of the as-welded joints (a) and (b) reached about 150MPa, and fracture occurred at the interface. However, after annealing at $500^{\circ} \mathrm{C}$ for $10 \mathrm{~h}$, the tensile strength of joints (c) and (d) reached about $400 \mathrm{MPa}$, and rupture occurred on the high-Nb TiAl alloy side. This phenomenon shows that post-weld treatment is important to improve the friction welding joint tensile strength.

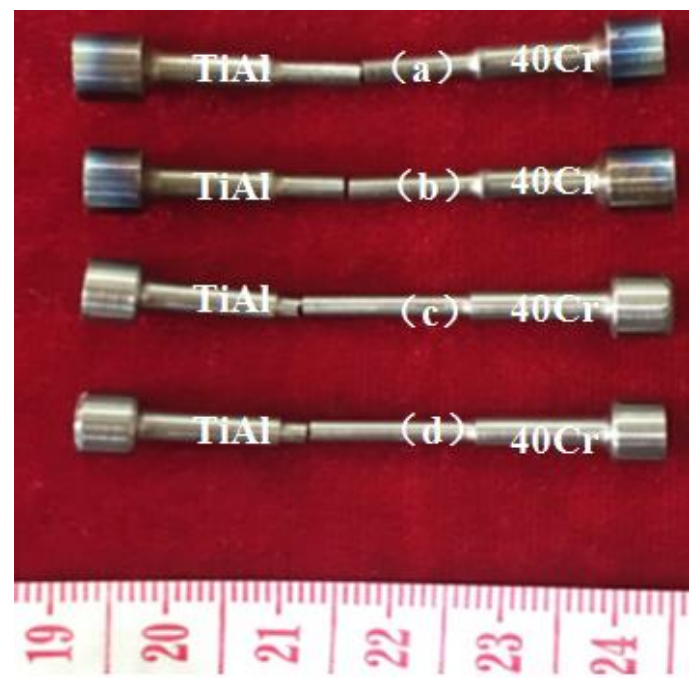

Figure 2: Welded joints state: (a) and (b) as-welded, (c) and (d) annealing after tensile test.

Figure 3 shows the microhardness distribution around the friction welded interface as welded and annealing state. It can be seen that the microhardness of the welded interface is much higher than those on the $40 \mathrm{Cr}$ steel and high-Nb TiAl alloy in as-welded state. The formation of carbides at the interface during welding process, which enhanced the hardness [7]. However, the hardness reduced significantly after annealing at $500^{\circ} \mathrm{C}$ for $10 \mathrm{~h}$.

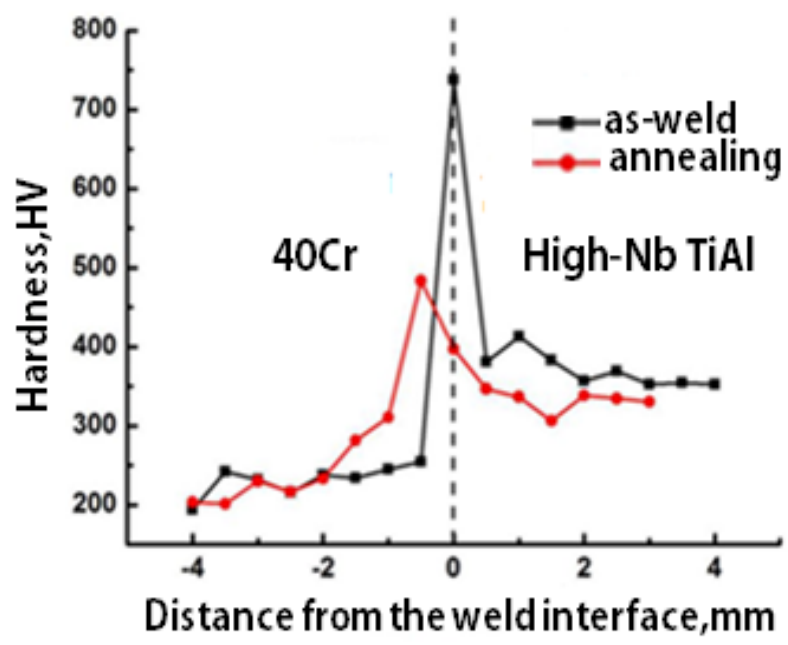

Figure 3: Microhardness distribution around the friction welded interface.

\subsection{Microstructure}

The XRD patterns of the high-Nb TiAl alloy are shown in Figure 4. The three phases of $\gamma, \alpha_{2}$, and B2 were observed to exist in the high-Nb alloy. The backscattered electron (BSE) image in SEM for the high-Nb TiAl alloy is shown in Figure 5. It can be seen that the lamellar colonies (region 2), $\gamma$ grains (region 3), and B2 phase (region 1) exist at the colony boundaries and the triple junctions.

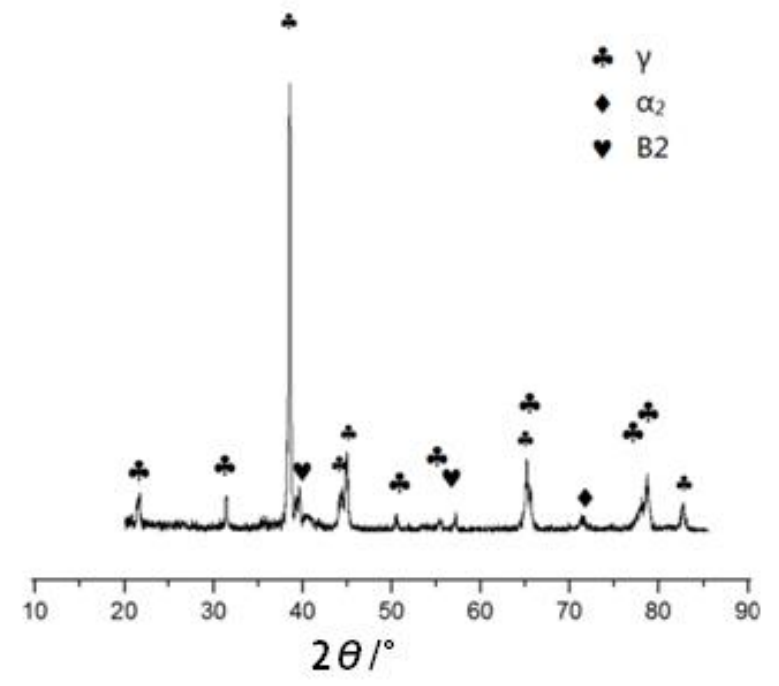

Figure 4: XRD pattern of high-Nb TiAl alloy

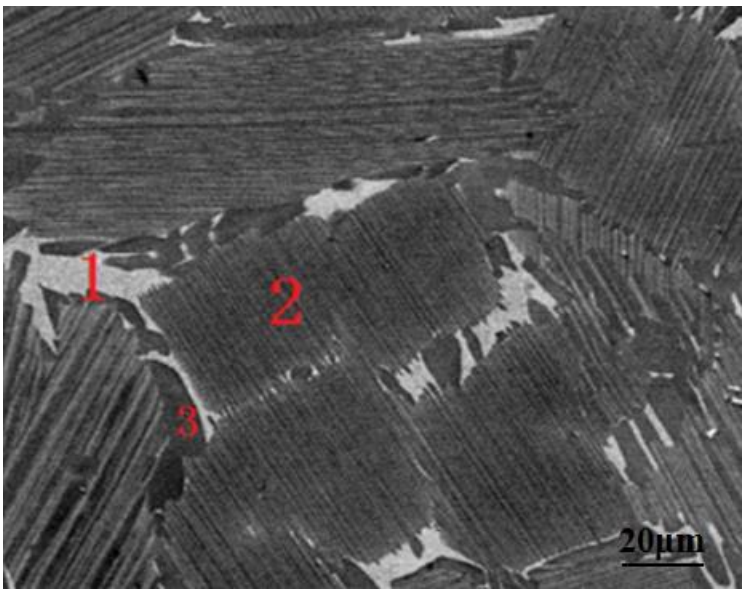

Figure 5: BSE image of high-Nb TiAl alloy

The compositions of the three point measured by EPMA are shown in Table 1. It can be seen that the content of Nb in B2 Phase is richer than that in $\gamma$ grains and lamellar colonies.

Table 1: Compositions of the three region in Figure 5

\begin{tabular}{|llll|}
\hline region & Ti/at.\% & Al/at.\% & Nb/at.\% \\
\hline 1 & 47.68 & 43.20 & 9.12 \\
2 & 44.70 & 47.02 & 8.28 \\
3 & 44.93 & 47.36 & 7.71 \\
\hline
\end{tabular}

The microstructure of the joints in the as-welded state is shown in Figure 6. It can be seen that the solid joint between high-Nb TiAl alloy and $40 \mathrm{Cr}$ steel can be successfully achieved using the friction welding method.

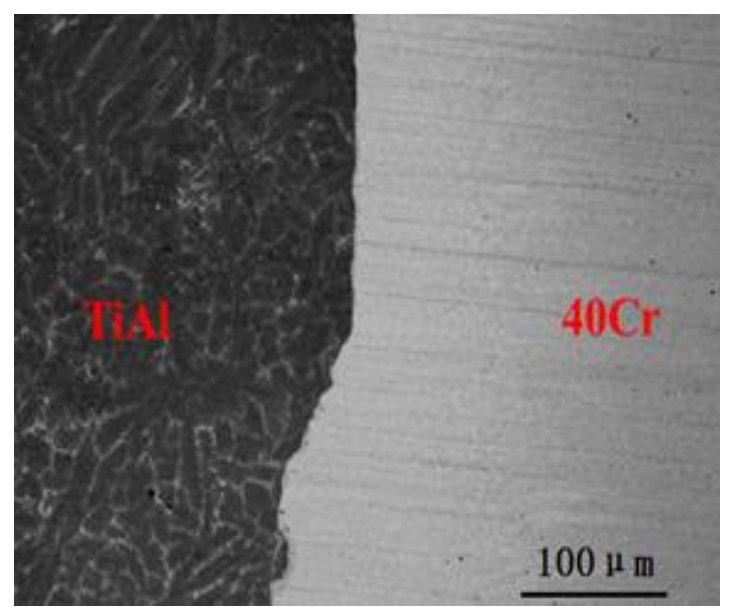

Figure 6: Microstructure of the interface of the joint 


\subsection{Fracture morphology}

The fracture morphologies of the as-welded and annealing-state samples are shown in Figure 7. It can be seen from Figure 7 that the cleavage fractures were observed on the fracture surfaces of the as-welded and annealing-state joints, indicating a brittle feature.

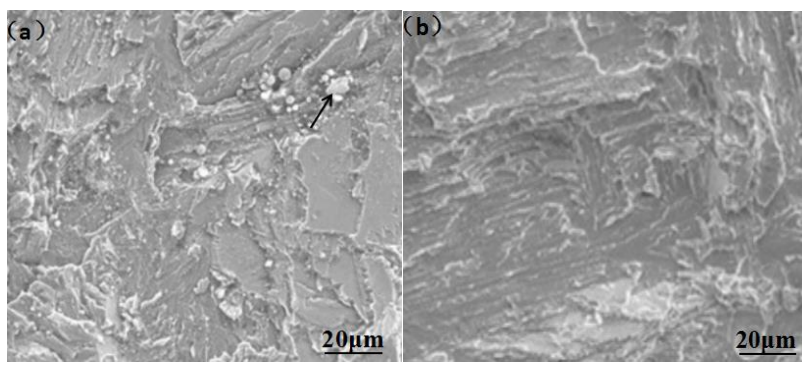

Figure 7: Fracture morphology of samples in (a) as-welded and (b) annealing states

A bulk is denoted by an arrow in Figure 7(a). The compositions of this bulk was measured using EPMA and are given in Table 2. It can be seen that the content of $\mathrm{C}$ is higher than that in $40 \mathrm{Cr}$ steel. This result confirms that the formation of carbides at the interface during the welding process.

Table 1: Compositions in Figure 7(a) shown by arrow

\begin{tabular}{|lllll|}
\hline Ti/at.\% & $\mathrm{Al} /$ at.\% & $\mathrm{Nb} /$ at.\% & $\mathrm{Fe} /$ at.\% & C/at.\% \\
\hline 30.63 & 23.14 & 2.46 & 22.5 & 21.27 \\
\hline
\end{tabular}

\section{CONCLUSION}

The high-Nb TiAl alloy used in this study is consist of $\gamma, \alpha_{2}$ and B2 phases. $\mathrm{Nb}$ is richer in B2 Phase than in $\gamma$ grains and lamellar colonies. Solid joint between high-Nb TiAl alloy and 40Cr steel could be obtained sucessfully using friction welding method. The tensile strength of the as-welded joint reached about $150 \mathrm{MPa}$, and fracture occurred at the interface. However, after annealing at $500^{\circ} \mathrm{C}$ for $10 \mathrm{~h}$, the tensile strength of the joint reached about $400 \mathrm{MPa}$, and fracture occurred on the high-Nb TiAl alloy side. The cleavage fractures were observed on the fracture surfaces of the as-welded and annealing-state joints, indicating a brittle feature. The microhardness at the welded interface is much higher than those on the $40 \mathrm{Cr}$ steel and high-Nb TiAl alloy in as-welded state. The formation of carbides at the interface during welding process, which enhanced the microhardness. However, the microhardness reduced significantly after annealing at $500^{\circ} \mathrm{C}$ for $10 \mathrm{~h}$.

\section{ACKNOWLEDGMENTS}

This work was supported by the projects of the National Natural Science Foundations of China (21271084) and of Jilin Province (20160101290JC), and Changbai Mountain Scholar Distinguished Professor (2015047).

\section{REFERENCE}

[1] Wu, X.H., Hu, D., Loretto, M.H. 2004. Alloy and process development of TiAl. Journal of Materials Science, 39 (12), 3935-3940. doi: 10.1023/B:JMSC.0000031474.29156.17*

[2] Aldaihani, N., Alenezi, R. 2017. Estimation of CO2 Emissions of The Vehicles Transport Sector In The State Of Kuwait. Acta Chemica Malaysia, $1(1), 08-12$.

[3] Liu, Z.C., Lin, J.P., Li, S.J., Chen, G.L. 2002. Effects of $\mathrm{Nb}$ and $\mathrm{Al}$ on the microstructures and mechanical properties of high $\mathrm{Nb}$ containing TiAl base alloys. Intermetallics, 10 (7), 653-659. doi: 10.1016/S09669795(02)00037-7*

[4] Elsayed, J. 2017. Bio-Chemical Biomarkers In Algae Scenedesmus Obliquus Exposed To Heavy Metals Cd, Cu And Zn. Acta Chemica Malaysia, 1 (1), 16-20.

[5] Dong, H.G., Yang, Z.L., Dong, C. 2013. Vacuum brazing of TiAl alloy to $40 \mathrm{Cr}$ steel with $\mathrm{Ti}_{60} \mathrm{Ni}_{22} \mathrm{Cu}_{10} \mathrm{Zr}_{8}$ alloy foil as filler metal. Materials Science and Engineering: A, 561, 252-258. doi: 10.1016/j.msea.2012.11.014*

[6] He, P., Feng, J.C., Zhang, Y.Y., Run, Z.J. 2002. Microstructure and strength of diffusion bonded joints of TiAl base alloy to steel. Materials characterization, 48, 401-406. doi: 10.1016/S1044-5803(02)00319-4*

[7] Lee, W.B., Kim, M.G., Koo, J.M. 2004. Friction welding of TiAl and AISI4140. Journal of materials science, 39 (3), 1125-1128. doi: 10.1023/B:JMSC.000*

\section{ABOUT THE AUTHORS}

Xin Wang was born on August 18, 1991, in Anhui, China. He earned a bachelor's degree from Beijing University of Chemical Technology in 2014 and a master's degree in 2017 from University of Science \& Technology Beijing. He taught at Jilin Institute of Chemical Technology (JLICT) in China. His research areas are Friction welding and investment casting of high-Nb TiAl alloy.

Professor Dayong Lu was born on July 31, 1967, in Liaoning, China. He earned a bachelor's degree in 1989 and a master's degree in 1996 from Jilin University and a PhD from Yamagata University in 2005. He taught at Jilin Institute of Chemical Technology (JLICT) in China. His research areas are high-permittivity ceramic materials, pharmaceutical analysis and quality control of traditional Chinese medicines, temperature-dependent measuring technology, and inorganic-organic composite materials. He is President of College of Materials Sciences and Engineering, Academic Leader of Materials Science and Engineering discipline, JLICT, Director of Key Laboratory of Special Functional Materials in Jilin Provincial Colleges and Universities. He was awarded New Century Excellent Talents in University, State Education Ministry (2007); Changbai Mountain Scholar Distinguished Professor (2016); and State Department Special Allowance (2015).

Minghao Liang was born on June 27, 1997, in Jiangsu, China. He is an undergraduate in Jilin Institute of Chemical Technology. Her research area is high-Nb TiAl alloy. 